\title{
India downgrades family planning research
}

India's government has slashed funding for an experimental contraceptive vaccine that had attracted widespread international interest. The cut, which took effect last month, comes amid signs that the second most populous country in the world is losing interest in reproductive research.

Gursaran Prasad Talwar, former director of the National Institute of Immunology (NII) in New Delhi, has been developing the vaccine over the past two decades. The vaccine immunizes women against human chorionic gonadotrophin (hCG) and is the first that has been shown to prevent pregnancy. An improved formulation was to be tested in large-scale, phase 3 trials soon.

But at a meeting of the task force of the Department of Biotechnology (DBT) at the end of March, officials decided to halve the project's annual grant to $\$ 100,000$ and downgraded it from one of sixteen high-priority "missions" to a regular "research mode" status. Talwar, now 70, who was told to relinquish leadership of the project in 1994 and now acts only as an unpaid adviser at the NII, believes that "jealousy and petty politics" are starving the project of finance and leadership.

"The Talwar vaccine is by far the most advanced antifertility method based on immunology," Sheldon Segal of the Population Council in New York told Nature Medicine. "If this vaccine is abandoned, it would be a tragedy."

The current director of the project, Sandip Basu, denies that the project is being deliberately slowed or abandoned. "There are several basic things about this hormone [hCG] that we do not know," he says. "We cannot allow this vaccine to enter phase 3 trials until its long-term safety is established."

The downgrading of the vaccine project is seen as symptomatic of a wider decline in contraceptive $R \& D$ in India. "People have lost interest in reproductive re- search," says V.K. Vinayak, a senior DBT official. In contrast to the past, when Indira Gandhi encouraged efforts in contraceptive $R \& D$, political will is lacking, even though India's population is growing by 56,000 per day. "Perceptions of family planning needs have undergone a sea change," says T. C. Anandkumar, who until last year was president of the Indian Society for Study on Reproduction and Fertility. In particular, following the 1994 Cairo international conference on population and development, there is a view that eradicating illiteracy and improving economic standards are more important than new contraceptives for reducing population growth.

The Indian Council of Medical Research, whose budget is $\$ 20$ million, allocates just 1.25 percent of its resources to basic research on contraceptives, compared with up to 15 percent in the early 1980 s.

K.S. JAYARAMAN New Delhi

\section{Cancer institute reverses mammogram advice}

The US National Cancer Institute has reversed its controversial advice on the benefits of screening women in their forties for breast cancer. Just weeks after a consensus panel convened by the institute concluded that there were no grounds for recommending regular screening in this age group (Nature Medicine 3, $255 ; 1997)$, the institute has now decided to urge all women aged 40 and over to have a mammogram every one to two years.

The U-turn, announced at the end of March, is a clear

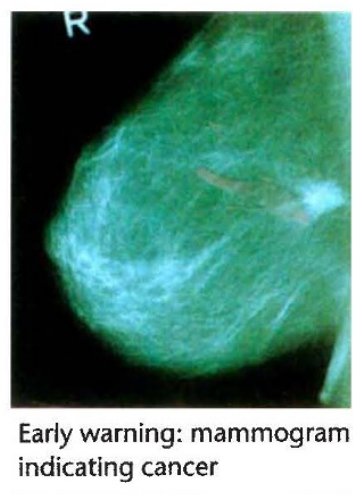

profound influence on cancer policy in the USA, and their announcements are likely to prompt fresh debates in other countries. Richard Klausner, director of the cancer institute, says that there is now "a lot of discussion" outside the US about the best age to start screening. Only 4 of 21 industrialized nations currently recommend mammograms for women in their forties: Iceland, Greece, Spain and Sweden. Most begin screening after the age of 50 .

The cancer institute's attempt to settle what has become one of the most volatile health issues in the USA. It came only days after the American Cancer Society recommended that women in their forties have mammograms annually, a warning that appeared to contradict the institute's earlier advice. The institute and the cancer society have now issued a joint statement which says they agree that regular screening for women in their forties is warranted.

Both the institute and the society have a decision was based on the conclusions of the National Cancer Advisory Board, a separate body from the consensus panel that produced the earlier advice. Members of the board said that they based their decision on a reexamination of new data from seven studies from around the world. The data, first released in January, suggested that, overall, women in their forties who had regular mammograms were about 17 percent less likely to die of breast cancer than those who did not.

Not all experts consider these findings significant. For example, the consensus panel had already reviewed the same data and had rejected them. But the advisory board's chair, Barbara Rimer, director of cancer prevention, detection and control research at Duke University in Durham, North Carolina, says that "the board concluded that there is enough evidence to support a woman's decision to begin screening in her forties."

The differences of opinion about the new data among researchers center on the difficulty of pinpointing the best time to screen in a disease where there is typically a delay of years between the earliest detectable sign of cancer and death. The difference in death rates between screened and unscreened women does not emerge until the late forties, so it is impossible to tell whether screening women in their early forties saves lives that could not have been saved by screening them later. Because of this uncertainty, the consensus panel did not call for regular screening, instead suggesting that women make their own decisions. The advice provoked intense criticism from the health commu- 